\title{
Development of Hydro Impulse Turbines and New Opportunities
}

\author{
Audrius Židonis, David S Benzon, George A Aggidis* \\ Lancaster University Renewable Energy Group and Fluid Machinery Group, Engineering Department, Lancaster LA1 4YR, \\ United Kingdom \\ *Corresponding author: g.aggidis@lancaster.ac.uk
}

\begin{abstract}
Hydro impulse turbines are often referred to as a mature technology having been invented around 100 years ago with many of the old design guidelines producing machines of a high efficiency. However with recent advances in Computational Fluid Dynamics (CFD) it is now possible to simulate these highly turbulent multiphase flows with good accuracy and in reasonable timescales. This has opened up an avenue for further development and understanding of these machines which has not been possible through traditional analyses and experimental testing. This paper explores some of the more recent developments of Pelton and Turgo Impulse turbines and highlights the opportunities for future development.
\end{abstract}

\section{Keywords}

Hydropower, Impulse turbines, Pelton turbine, Turgo turbine, Computational Fluid Dynamics, Optimisation

\section{Introduction}

The use of conventional power resources is the cause of more and more discussions with environmental impact being one of the concerns expressed by various international agreements $[1,2]$. In addition to the environmental issues, conventional power resources are subject to gradual depletion, strategic political influence and increasing cost. These are some of the reasons why renewables are becoming more competitive with conventional power sources [3]. Hydropower is a renewable power resource that converts the available energy in the river flow into mechanical energy and electricity. Despite the maturity of the technology, hydropower has not been used to its full potential. For example, there are studies showing that there is a capacity of $1.5 \mathrm{GW}$ (more than $4 \%$ of the average UK power demand [4]) of untapped hydro power available in the UK [5]. 


\section{Background}

\subsection{Reaction and Impulse Turbines}

A huge variety of hydro turbine types have been developed to accommodate specific requirements or available river conditions. The two distinct classes are reaction and impulse turbines. In general, the reaction turbines (e.g. Kaplan, Francis or Archimedes Screw) are used in locations that are not mountainous utilising relatively low heads and high flow rates. Impulse turbines (e.g. Pelton, Turgo or Cross-flow), on the other hand, were developed for medium to high head and low flow rate applications. The typical ranges of various turbines are presented in Fig. 1. Two of the impulse turbines, Pelton and Turgo, have many similarities as they both utilise a flow momentum available in a high speed water jet. Therefore, identical injector designs can be used in both of the turbines and the overall flow analysis problems are very similar.

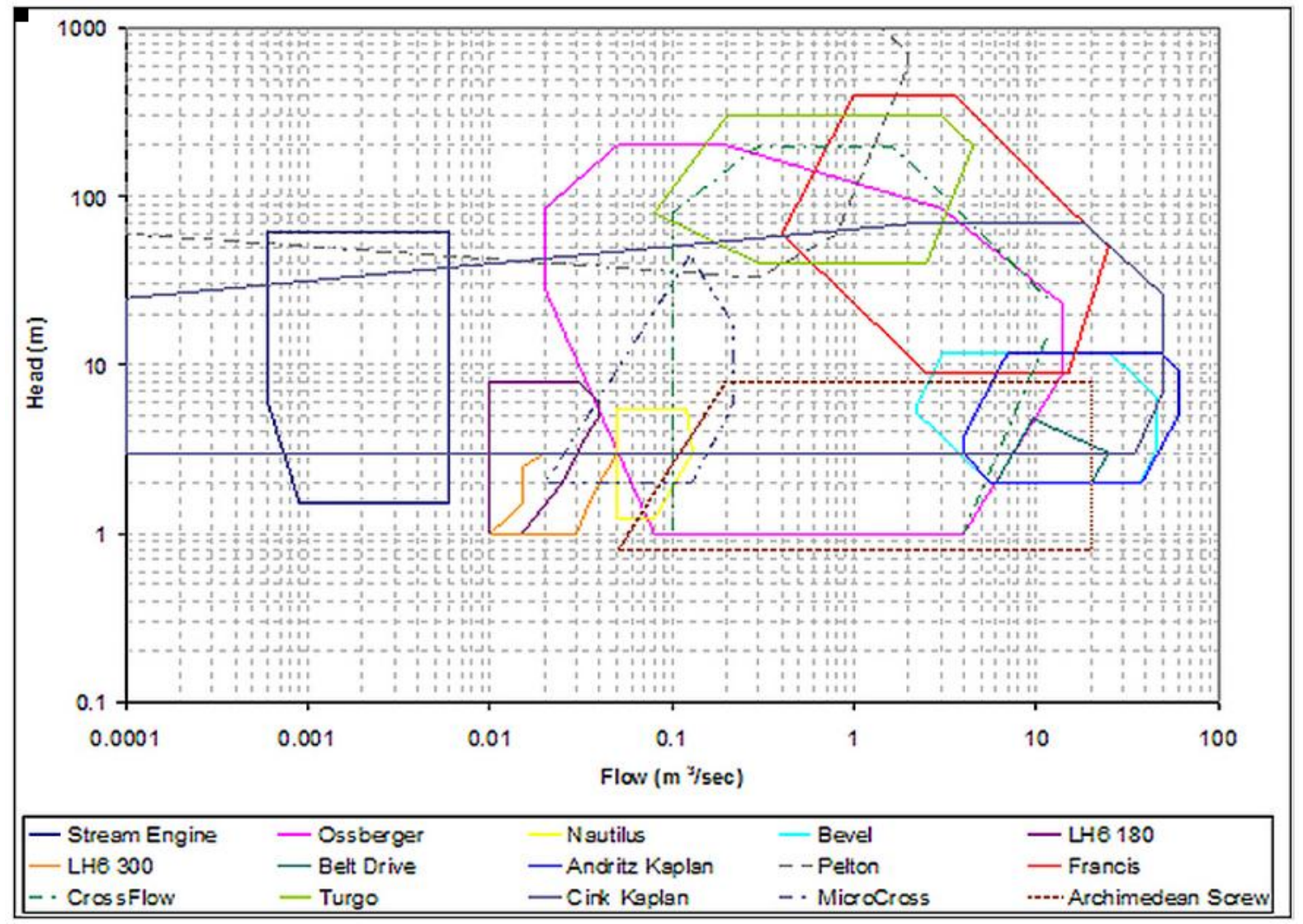

Fig. 1. Performance envelopes of hydro turbines $[6,7]$ 


\subsection{Pelton Turbine}

The Pelton turbine, invented by Lester A. Pelton [8] in is one of the most efficient impulse turbines. The power is produced by converting the potential power into a high velocity water jet and then utilising the water momentum impinging on the buckets $[9,10]$. Since the invention, the design of the Pelton turbine has seen continuous development [11] requiring new tools for analysis and optimisation. For most of its existence it was developed based on theoretical or empirical guidance that was either limited by various assumptions or required extensive experimental testing, a very complex task in itself [12], that includes large costs and very long time scales. However, recent publications show a rapidly increasing usage of numerical modelling known as Computational Fluid Dynamics (CFD) to better understand the details of the complex unsteady flow in the runner and the whole Pelton turbine.

\subsection{Turgo Turbine}

The Turgo Impulse turbine is a high capacity impulse turbine which utilises the same nozzle and spear injector system as the Pelton. By inclining the jet axially it allows more flow thorough the runner at a higher speed providing a machine suitable for use at head and flow rates usually reserved for Francis machines.

Since its invention nearly 100 years ago, the majority of the development of the Turgo turbine design has been through the use of paper-based and experimental studies. More recent advances in CFD have allowed the simulation of the complex flows encountered with impulse turbines to take place and some work has been done in applying this to the Turgo design.

\subsection{Difficulties in Impulse Turbine Modelling}

For more than 20 years now CFD has been successfully used to analyse and develop reaction turbines [13]. However, modelling of impulse turbines like Pelton or Turgo is still a challenging task due to difficulties such as the pressure losses, secondary flows, jets, film flow, free surfaces, spray formation, ventilation losses, unsteadiness and complex interactions between components [14]. Moreover, quasi-steady state approximations are not available for Pelton or Turgo turbine modelling which requires the use of completely unsteady time dependent simulations with rotor-stator interaction. Fortunately despite the difficulties, the technology is advancing and some promising results are available.

The main regions of interest are the distributor, nozzle, runner and casing. The distributor and nozzle design affect the jet quality which is very important for both efficiency of the whole system [15] and the operational life of the runner $[14,16,17]$. On the other hand, the turbine efficiency is highly dependent on the bucket (Pelton) of blade (Turgo) geometry, requiring an accurate technique to model 
the flow in a rotating runner. Finally, the impulse turbine casing design is also very important as it might cause flow energy losses due to disturbance of incoming jets interfering with water sheets that have not evacuated [18]. Simulation of the complete system that includes all the main sections is important but currently prevented by limiting factors such as the timescale or very high computational demands. For these reasons, compromises are introduced in order to achieve an optimum combination of accuracy and computational cost.

\section{Pre-CFD Development of Impulse Turbines}

\subsection{Pelton}

\subsubsection{History}

Impulse turbines available prior to the invention of Pelton turbine $[8,19,20]$ in 1880 were extremely inefficient. The first Pelton turbine consisted of rectangular shape buckets with a splitter to symmetrically divide and deflect the jet flow back almost through $180^{\circ}$. Later, in the first half of the XX century, Pelton turbines evolved into something more similar to what is currently used: a cutout was made at the front of the bucket and injectors were designed to include the spear valve and vertical shaft arrangement of the multi-jet operation (Fig. 2). Fig. 3 presents the typical modern Pelton turbine. The bucket geometry has evolved into a much smoother round shape and the buckets have a cutout that ensures better transition as the jet goes from one bucket to another. In addition, the flow rate is controlled by the spear valve ensuring good jet quality.

First CFD results of Pelton jet simulation were published [21-24] by the end of the XX century and were followed by more publications later on [16, 25]. Before CFD application, impulse turbines were developed using a graphical method [26, 27]. Numerically modelled jet and bucket interaction [28-30] appeared few years after the first free jet simulations were presented. These results looked promising in terms of CFD application of Pelton turbine development. However, only few publications present the design optimisation based on numerical results. This issue regarding the absence of publically available numerically based and experimentally validated Pelton optimisation results was addressed by Solemslie and Dahlhaug in 2012 [31]. 


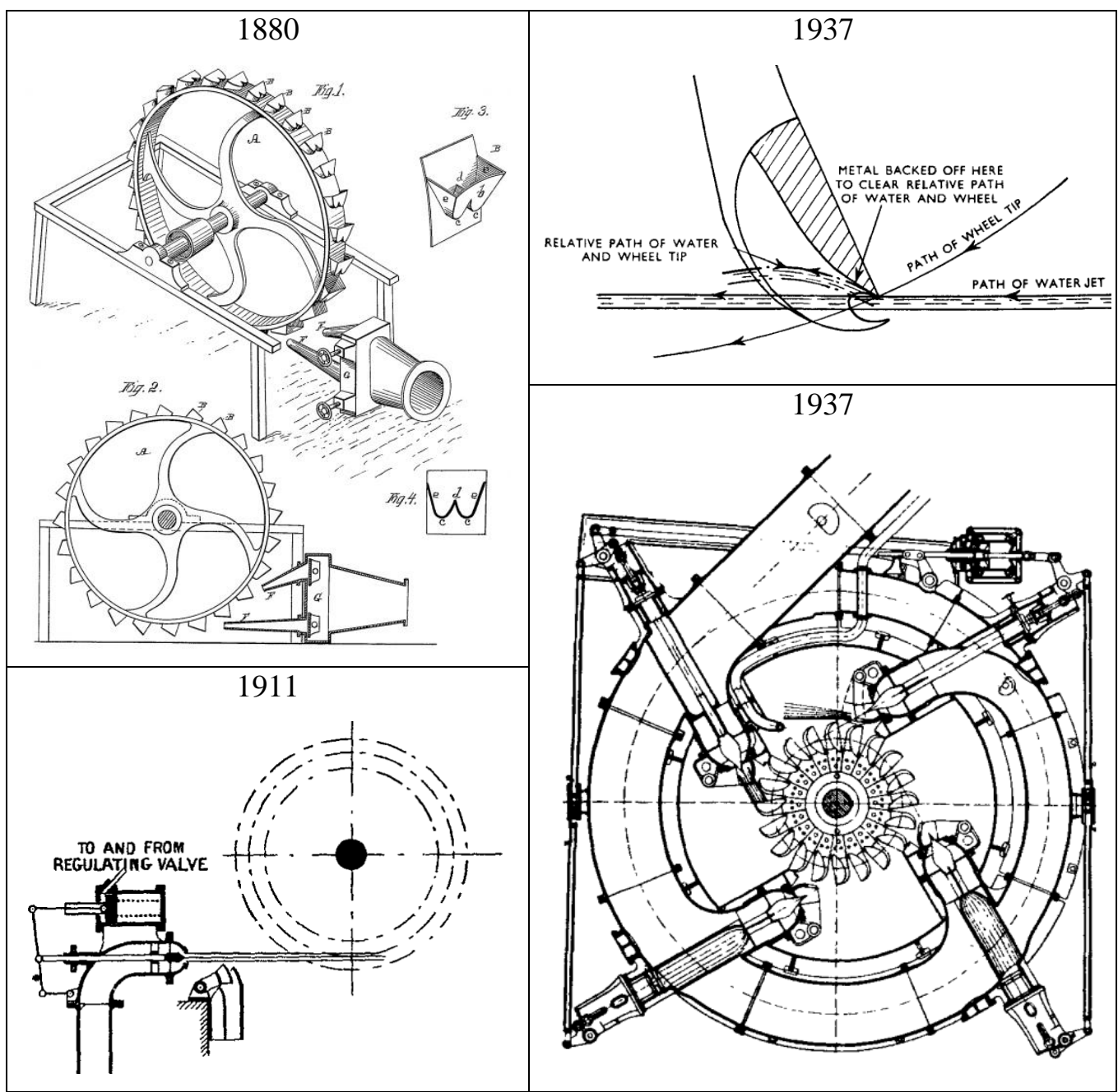

Fig. 2. Illustrations of the Pelton wheel from its patent [8] and further modifications [32, 33]

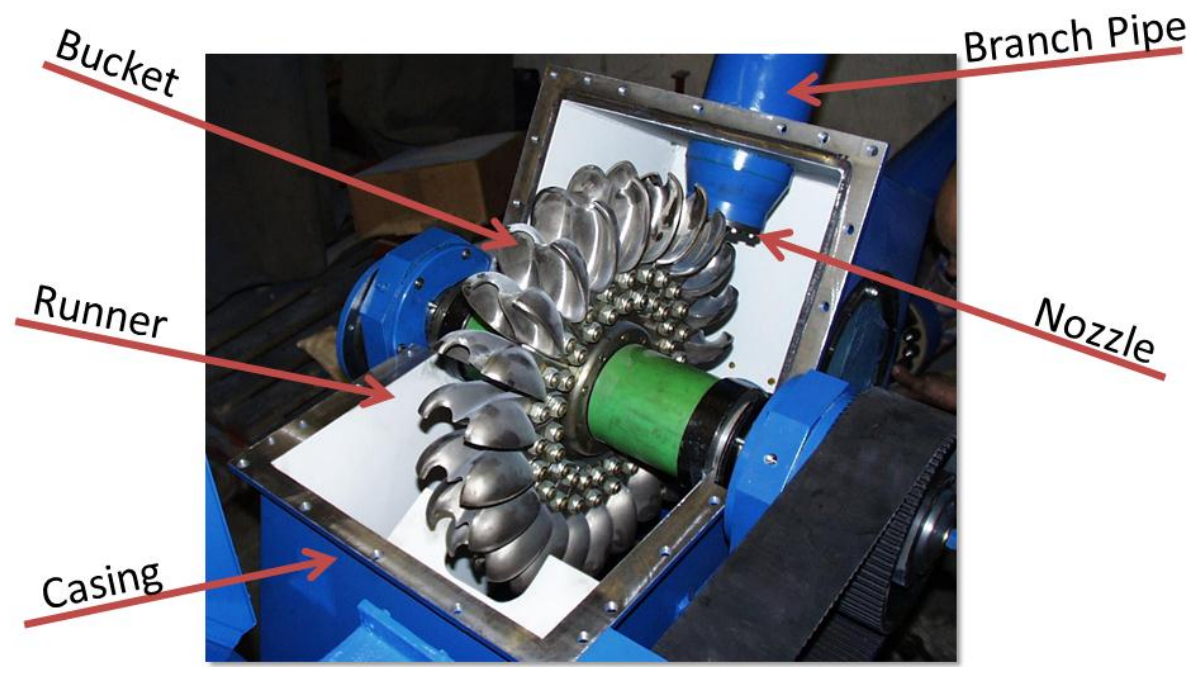

Fig. 3. Typical layout of modern Pelton turbine [34] 


\subsubsection{Available Design Guidelines}

Pelton turbines have been developed for more than a century now and there is a vast amount of available design guidelines. The classics of Pelton turbine designing are available in the textbook by M. Nechleba Hydraulic Turbines: Their Design and Equipment [9] that was published in 1957. Even though modern commercial turbines and their designing trends have evolved since then, the theoretical calculations or equations for analysis of Pelton turbine performance provided in this publication are still applicable. More recent guidelines on Pelton turbine designs can be found in Water Power Development by E. Mosonyi [10], MHPG Series: Harnessing Water Power on a Small Scale. Volume 9: Micro Pelton Turbines by M. Eisenring [35] or The Micro-Hydro Pelton Turbine Manual by J. Thake [36].

In addition, there are some journal publications that include design guidelines for Pelton turbines $[37,38]$. However, usually it is not known what kind of research these guidelines are based on as most of the experimental data is not available to the public and is kept as commercial secret by the turbine manufacturers [31]. Nevertheless, the guidelines are based on theoretical calculations and assumptions and are usually in agreement with the commercial product designs of the leading turbine manufacturers.

\subsection{Turgo}

\subsubsection{History}

The Turgo Impulse turbine was invented in 1919 by Eric Crewdson as higher specific speed version of the popular single jet Pelton which existed at the time. The design is described in British Patent No. 155,175, and in the 1922 Institute of Civil Engineers conference proceedings paper Design and Performance of a New Impulse Water-Turbine [39]. The paper describes the invention as a development of the axial flow Girard turbine (Fig. 4) incorporating a Pelton type jet. The Girard turbine is an axial flow impulse machine where the head at the inlet is converted into kinetic energy by passing the flow through guide passages, $\mathrm{P}$, producing high velocity streams [40]. 


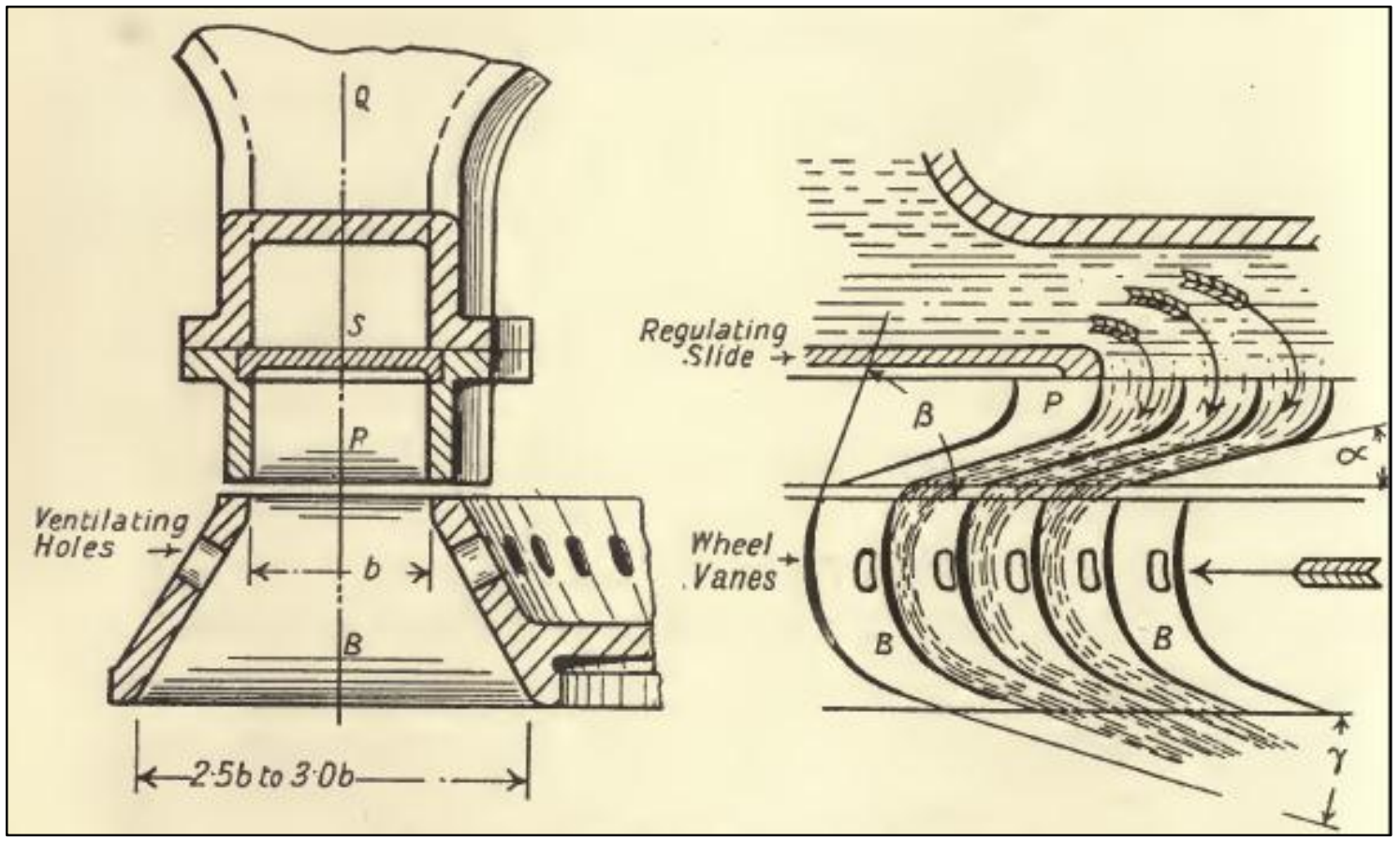

Fig. 4. Axial flow Girard turbine [40]

At the time, the diameter of the jet of a Pelton wheel was restricted to around $1 / 10^{\text {th }}$ of the runner diameter: a D/d ration of 10:1, anything above this would affect the turbine efficiency. The Turgo design allowed a much larger diameter jet to be applied to the turbine without losing efficiency [41]. This is achieved by the jet impacting the runner at an angle from the front side and expelling water out of the back (Fig. 5).

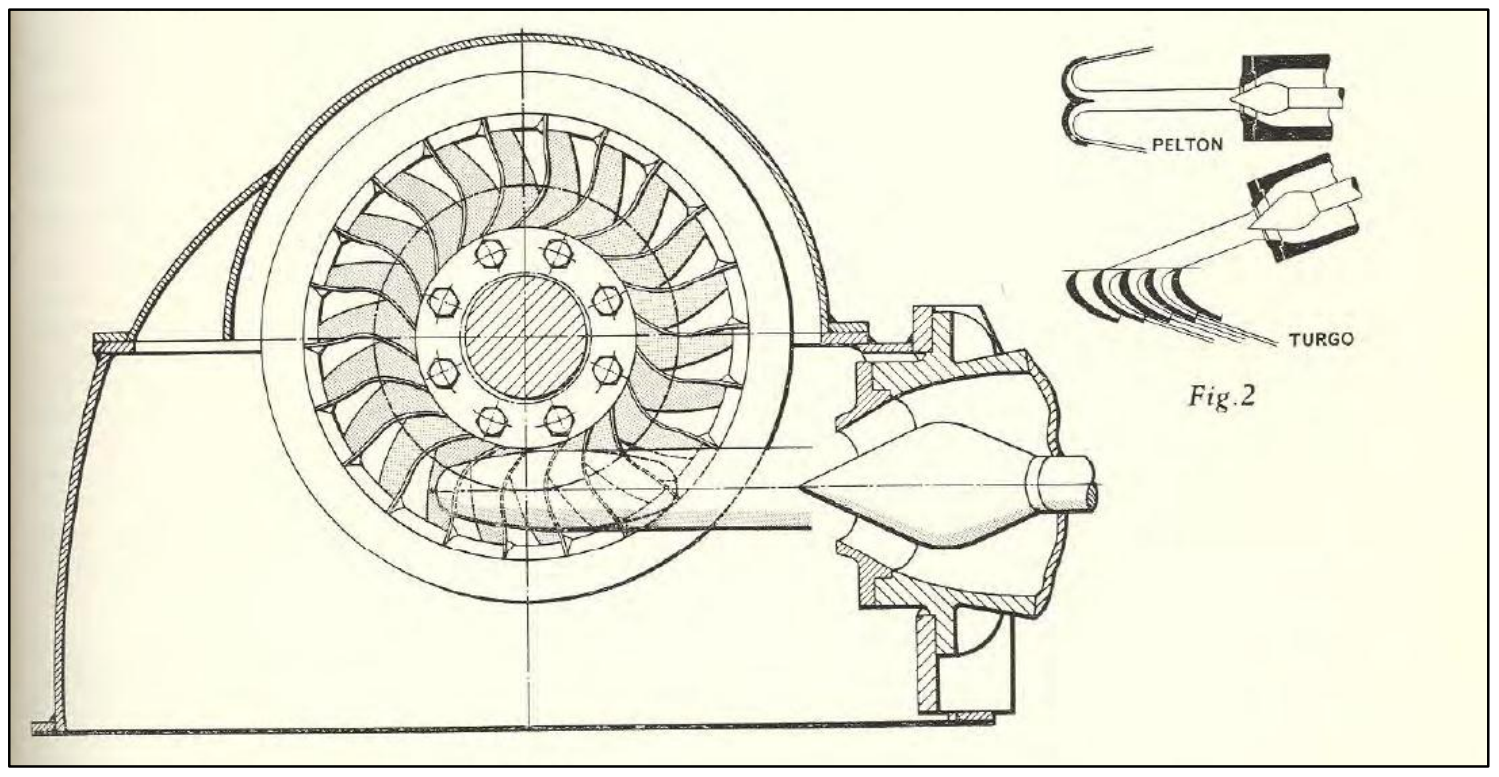

Fig. 5. Pelton and Turgo jet positioning showing inclined nature of Turgo jet [41] 
The resulting runner design is shown in Fig. 6, below. The Turgo design was tested by Dr A. H. Gibson of Manchester University showing a maximum efficiency of $83.5 \%$ under a head of 200 feet, producing 106HP, at 640rpm [39].

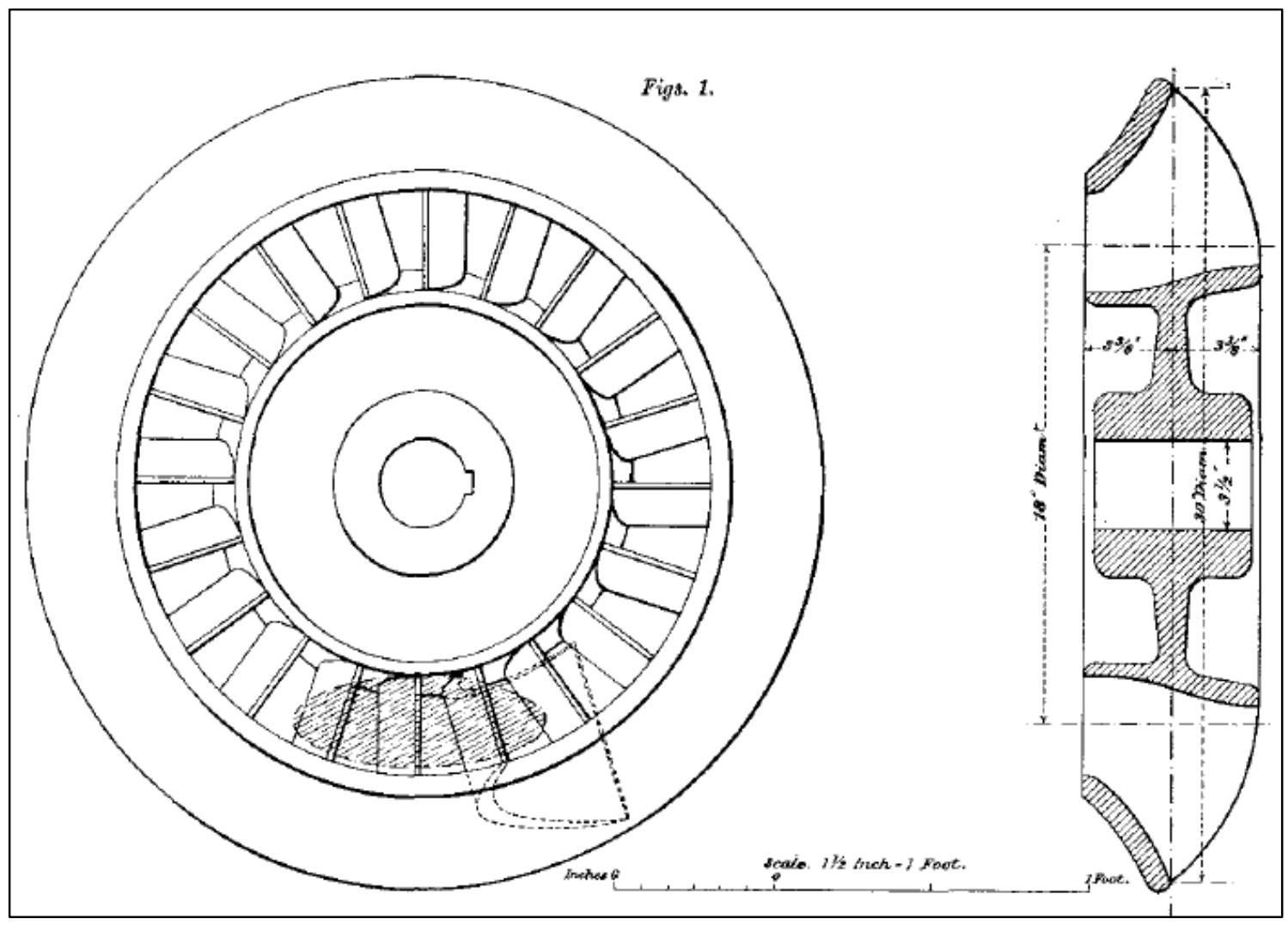

Fig. 6. Drawing of the 1920 Crewdson Turgo design showing the inlet plane and cut section with the jet trace on the inlet wheel plane shaded [39]

This novel design was installed in locations throughout the world and developed a reputation for robust reliability particularly with water containing erosive particles making it a popular turbine for use in mining areas [41]. Further development of the Turgo was carried out by Ernest Jackson who was able to increase the capacity and performance of the Turgo using experimental methods. The details of these designs can be found in British Patent Number 468,557 of July the $7^{\text {th }} 1937$ and British Patent Number 938967 of $2^{\text {nd }}$ May 1961 [41].

Further Analysis of the Turgo turbine was carried out by James Webster in the early 70's detailed in three papers published in Water Power [42-44]. Webster developed a one-dimensional model to try and account for the losses in the Turgo runner by comparing it to a Pelton design [42] and took this work further using a graphical analysis [43] and detailed experimental testing and flow analysis [44]. 


\subsubsection{Available design guidelines}

There is very little in the way of design guidelines for Turgo turbines as the Patent was held by Gilbert Gilkes and Gordon Ltd. for over 50 years and most of the development during this time was carried out internally and not published. Some basic guidelines are given in the 1922 paper by Eric Crewdson [39] such as details of suggested radius and speed ratios and more specific design details are provided in the Patents [45-47]. The blades were originally designed using velocity triangles for the inlet and outlet angles combined with a series of practical assumption with regards to the nature of the flow within the runner such as: Ensuring the blades are short enough to reduce frictional losses to the relative velocity, but long enough to prevent eddy losses due to the bending of the water as it travels across the blades. It was also noted that the exit angle was the most important consideration during the design of the runner as although a smaller angle would result in higher efficiencies due to less momentum being lost at the exit, reducing the angle too much would reduce the capacity of the turbine by restricting the flow though the runner. The importance of this feature is emphasised again by further studies carried on the Turgo [48, 49]. A value of no more than 10-15 degrees was suggested for good results. A point is also made that the exit angles can be made considerably smaller than would appear from theory with the experiments showing the discharge angle to be courser than the exit angle of the blade [39].

A more recent design methodology for a Turgo is suggested by Correa et al in 2012 using Rankine Oviods [50] and the effects of speed ratio and jet alignment are investigated experimentally for the Pico Hydro scale [51].

\section{Application of CFD on Impulse Turbines}

Currently accurate numerical modelling of impulse turbines is achieved using ANSYS CFX and ANSYS Fluent commercial codes. Even though a large portion of publications concentrate on the Pelton turbine [52], some of the simulations presented under Pelton can be directly applied to the Turgo since it uses identical or very similar injectors to Pelton turbines. The following sections review publications on impulse injector simulations, Pelton runner simulations and Turgo runner simulations.

\subsection{Impulse Turbine Injector and Jet Simulations}

One of the earliest publications on modelling the impulse turbine injector performance used CFX-4 and compared the jet velocity profiles to measurements acquired using LDA [22]. Turbulence model used for simulations was $\mathrm{k}-\varepsilon$ and the multiphase model was Homogeneous. The numerically and experimentally obtained velocity profiles corresponded very well. 
A case study was performed to improve the injector design and increase the overall efficiency of a Pelton turbine using Fluent [53]. The chosen turbulence model was k- $\varepsilon$ RNG and multiphase was modelled using Volume of Fluid method (VOF). Since the runner design was also modified it is difficult to know the exact contribution of the new nozzle design. Nevertheless, the overall efficiency was successfully increased.

A free jet impinging on a stationary flat plate and a rotating runner made of flat plates was studied using Fluent 6.1.18 [54]. The turbulence model used was k- $\varepsilon$ and the multiphase flow was modelled using VOF.

Research on Pelton turbine jets that included modelling of flow in a branchpipe, nozzles and a free surface jet was performed with CFX using the k- $\omega$ Shear Stress Transport (SST) turbulence model and a Homogeneous free-surface multiphase model [55]. Conclusions of this study suggested that there is a relationship between the runner efficiency and the jet dispersion caused by the upstream bends.

Impulse injector needle erosion was modelled and compared to the abrasion field observations [56] using Fluent. VOF and k- $\varepsilon$ RNG settings were selected for modelling. The sediment was simplified into round solid particles and the discrete particle model (DPM) was employed to predict the needle abrasion characteristic.

An optimization study of impulse injector design was performed using CFX and Fluent [57]. CFX simulations used k- $\omega$ SST turbulence model and the Homogeneous free surface multiphase model. Fluent used k- $\omega$ SST turbulence model and the VOF multiphase model. Numerical results produced by both codes suggested that much steeper nozzle and spear valve angles than currently used could reduce the losses in the injector and reduce secondary velocities in the jet.

\subsection{Pelton Runner}

There is a vast amount of publications on modelling of the Pelton turbine runner. These range from simple steady state problems of jet interaction with a stationary bucket to much more complex simulations where a complete rotating runner is interacting with one or more jets. Researchers have looked at various CFD applications from generic studies of rectangular shaped jet interaction with the runner to applied research where CFD is used to investigate the important design parameters for a Pelton runner and optimise its performance. Most of the simulations were performed using ANSYS CFX or ANSYS Fluent commercial software packages however there are attempts to use alternative CFD codes.

Modelling of a Pelton runner started as stationary bucket simulations before more complex cases of a runner in rotation were analysed. A study using Fluent on the stationary bucket case was performed 
where the chosen multiphase model was VOF and the turbulence model was k- $\varepsilon$ [58]. Excellent agreement to the experimental results was reported at most locations except at the cutout.

Another study using the stationary bucket was performed using both CFX and Fluent [59]. Excellent agreement between the codes was shown. Moreover, the numerical results were compared with experimental data in terms of water film thickness, visual observation, static pressure at the wall and total pressure sweeps and some discrepancies were observed.

There are investigations of different unnatural shape jets (rectangular, triangular or elliptical) interacting with stationary bucket [60] or a rotating runner in multi-jet operation [61]. CFX code was used choosing k- $\omega$ SST turbulence model and Homogeneous multiphase model.

From the stationary bucket cases, simulations went to more complex cases of the rotating bucket or runner. Research comparing the experimental and numerical results where an ideal jet was striking a rotating runner [62] was performed using CFD-5. A homogeneous model was chosen for the multiphase and the turbulence was modelled using $k-\varepsilon$ which was reported to have difficulties when modelling the flow around the cut-out. A 7.5\% contribution to the total torque caused by the Coanda Effect [63] which was observed on the backside of the bucket was shown numerically however, the amount could not be validated experimentally since all the 5 pressure taps were placed on the inside of the bucket. The reported discrepancy between experimental and numerical results was 5\%. The contribution of the outside surface to the total torque was numerically and experimentally observed by another study [30].

Later research [63] where CFX-10 code with Homogeneous multiphase model with k- $\omega$ SST turbulence model was used for simulations of an ideal jet striking 7 buckets of the runner also identified the Coanda Effect. By comparing this to the experimental results it was clear that there was an issue in accurately predicting the amount of torque caused by the suction of the jet separating from the outside surface of the bucket.

There is a study [64] that used an Inhomogeneous multiphase model with $k-\omega$ SST in CFX-11 despite the publications reporting slightly higher computation demands of the Inhomogeneous model $[28,58$, 65]. The importance of modelling a real jet was highlighted and a disagreement $6 \%$ between the numerical and experimental results was claimed.

Using a supercomputer with 2048 processor cores half of the runner was modelled assuming symmetrical behaviour of the flow at several operating points [66, 67]. CFX-12.1. code was used with $\mathrm{k}-\omega$ SST model for turbulence and Homogeneous model for the multiphase. The disagreement between numerical and experimental results was $4 \%$. Accurate simulation of the jet and the mesh density were identified as the main factors affecting total the accuracy. 
A study claiming a discrepancy of $1.5 \%$ between the numerical and experimental results was performed using CFX 13.0 with Homogeneous and k- $\omega$ SST models [68]. Only 3 consecutive buckets were used to represent the torque of the whole runner.

Another case of modelling the Pelton turbine using 3 consecutive buckets was published where CFX code was used [69]. A homogeneous model was selected for multiphase modelling. A comparison of

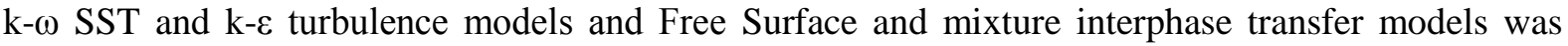
provided showing that the k- $\omega$ SST with the Free Surface method is best.

A study modelling half of the runner geometry divided by the symmetry plane boundary was performed using CFX 13 [56]. k- $\omega$ SST turbulence model and Homogeneous multiphase model were used. The results from CFD simulation were compared to the experimental results showing that the numerically predicted efficiency drops quicker than the experimental. A very similar study was performed using Fluent 13 [70]. The realizable k- $\varepsilon$ turbulence model was used. This study also showed similar comparison between experimental and numerical results.

Application of CFD to parametrically optimise the Pelton runner performance was shown in two analogical case studies where CFX 14.0 and Fluent 14.0 were used on two different specific speed Pelton runners [71]. The turbulence model was k- $\omega$ SST and the multiphase was modelled using a Homogeneous model in CFX and a Volume of Fluid model in Fluent. To reduce the timescale only 2 consecutive buckets were used to represent the torque of the whole runner and the individual effect of 11 design parameters were compared and discussed.

\subsubsection{Alternative CFD Codes}

All the publications reviewed above used ANSYS CFX or ANSYS Fluent to perform simulations. However, there were various attempts to model Pelton turbines using alternative codes. Some researchers are suggesting that OpenFOAM [72], a popular open source mesh based (Eulerian) code, might be used to model Pelton impulse turbine however, current simulations show that it is not there yet and that further development is required to model the Pelton turbine with acceptable accuracy within reasonable time scale [73].

There is a large amount of publications on using the Lagrangian approach (meshless) as an alternative to the conventional Eulerian (mesh based) methods. These Lagrangian approaches [74-76] usually involve particle tracking and are attractive because of drastically reduced time scales. However, they cannot compete with the mesh based solvers in terms of accuracy. Therefore considering the strengths and weaknesses of these meshless codes they can be used for the initial design stages [71]. The names of such codes used for Pelton turbine modelling are: Smoothed Particle Hydrodynamics (SPH) [77- 
79], Fast Lagrangian Solver (FLS) [80-82], Moving Particle Semi-implicit (MPS) method [83] and Finite Volume Particle Method (FVPM).

\subsection{Turgo Runner}

There has been relatively little development of the Turgo turbine using CFD however several studies of interest have been carried out. A Meshless Fast Lagrangian Solver (FLS) which treats the fluid as a number of particles and tracks the individual particle trajectories as shown in Fig. 7 was developed [49].

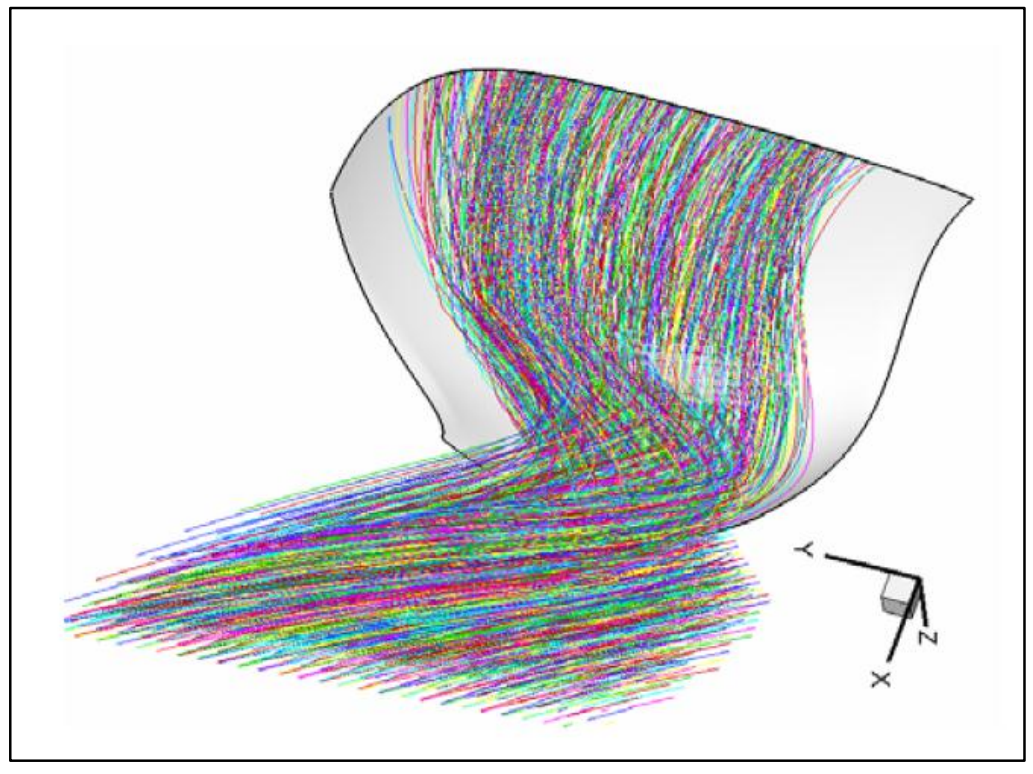

Fig. 7. Particle trajectories generated by the Lagrangian solver [49]

This FLS solver is coupled with general optimisation software, utilising genetic algorithms to optimise the shape of the blade. The results show an increase in efficiency of $6 \%$ between the standard and optimised runner with a maximum efficiency of $85 \%$.

Although this study develops a useful tool for the quick analysis of the flow across the inside surface of the blade it is unable to calculate the flow on the outside surfaces of the blades or the interaction between successive blades and therefore ignores a large proportion of the hydraulic losses within the runner.

This work was taken further with the development of a WCSPH algorithm to analyse the flow across the inside surface of a static Turgo blade [84]. This work was expanded on in 2011 where two Turgo blade geometries were compared using the SPH code developed and the commercial Eulerian solver ANSYS Fluent (Fig. 8). The comparison between the torque curves (Fig. 9) showed a good average correlation however the SPH results showed instability and some scattering. This study also only considers the torque on the inside surface of the blades [85]. 


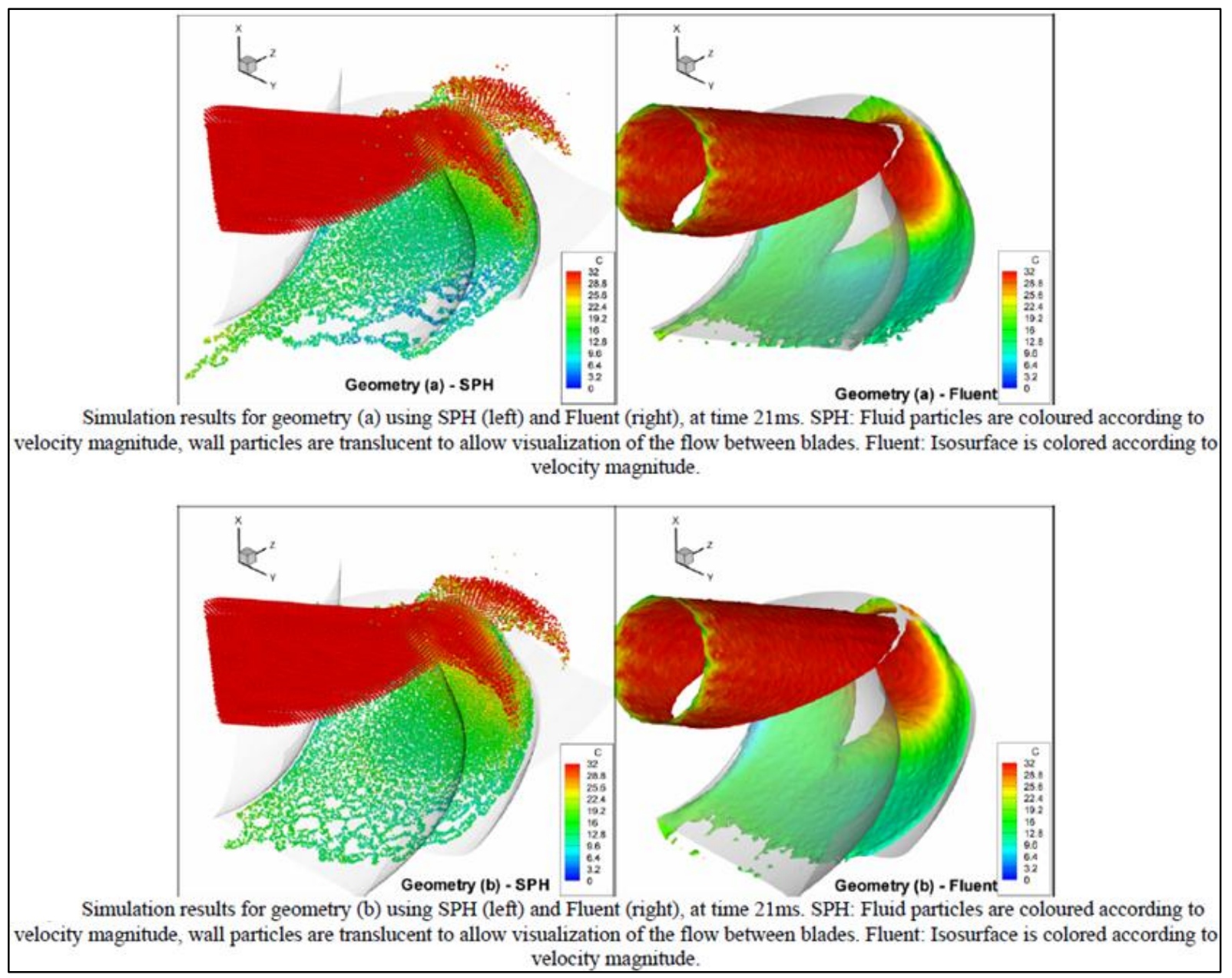

Fig. 8. Flow comparison between SPH and ANSYS Fluent for two blade geometries ((a) and (b)) [85]

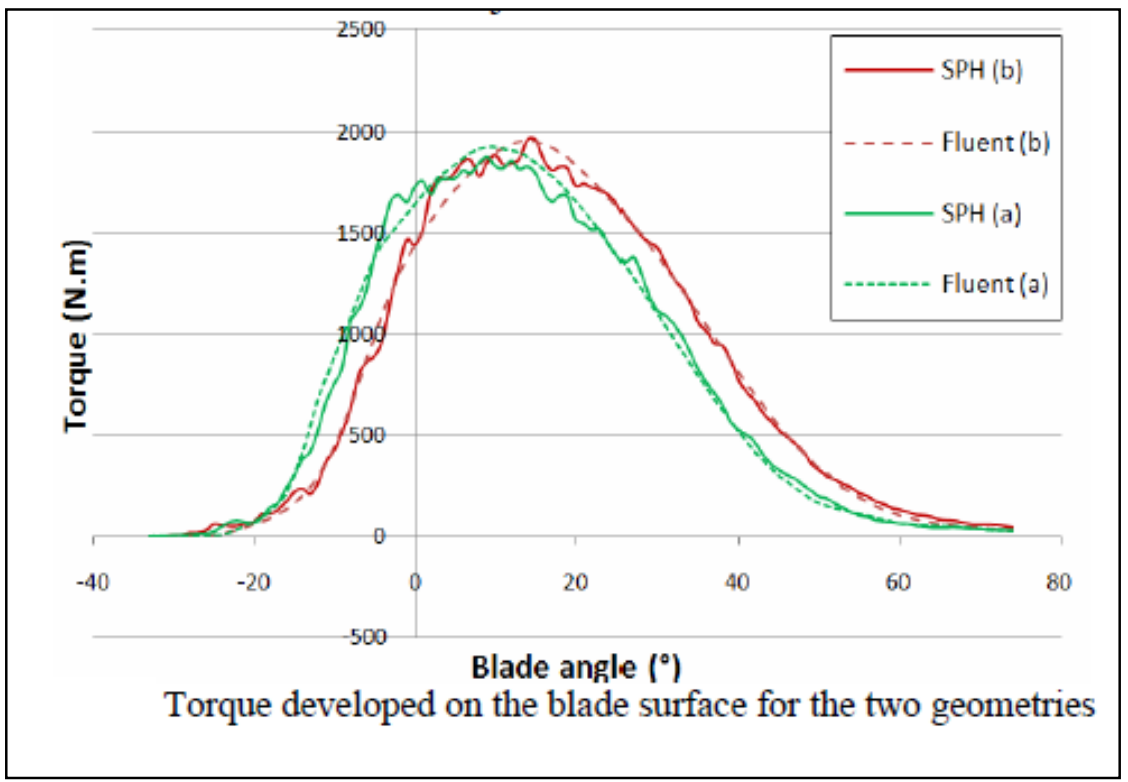

Fig. 9. SPH and ANSYS Fluent solvers Torque curve comparison for geometries (a) and (b) 
Optimisation of a Turgo runner is carried out using the FLS model with readjusted coefficients, based on the comparisons made between the FLS flow fields and the SPH flow fields, giving better agreement between the results (Fig. 10) as well as experimental testing of the optimised design [86].

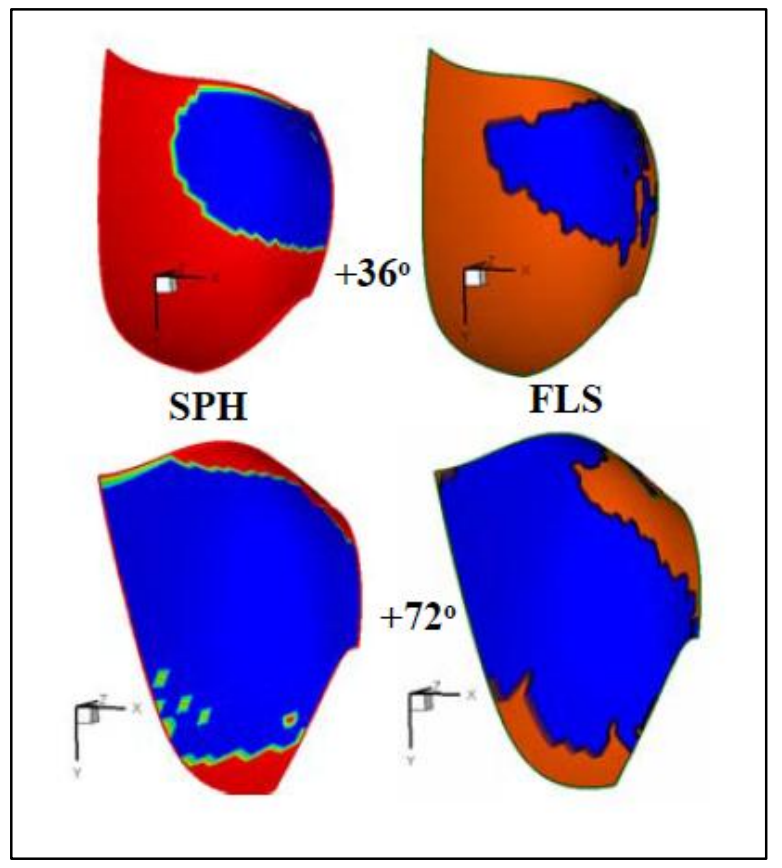

Fig. 10. Free surface flow comparisons between the adjusted FLS and SPH models [86]

The runner testing results showed that the best efficiency region includes the design point used in the optimisation and shows efficiencies over $85 \%$ (Fig. 11).

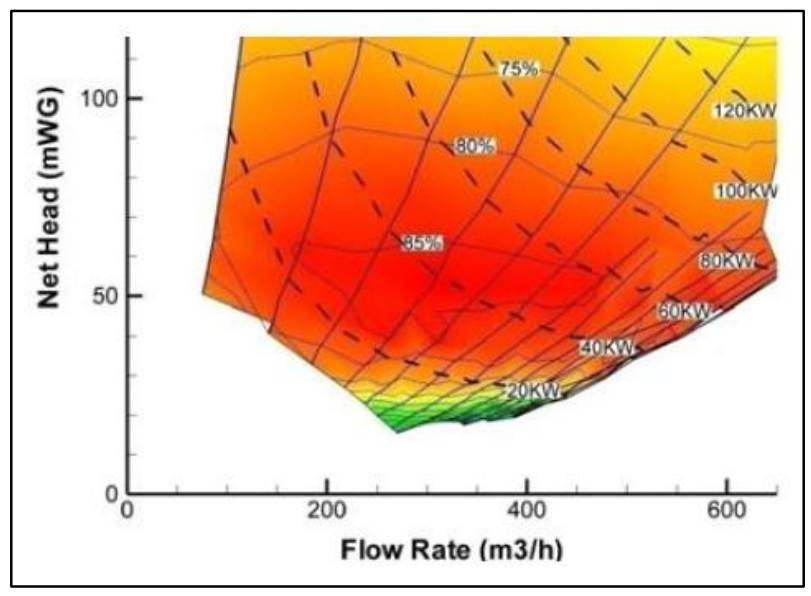

Fig. 11. Turgo efficiency hill chart for single upper jet operation [86]

The results also showed good correlation between the FLS model outputs and the experimental results assuming 3\% mechanical (shaft bearing and ventilation) losses (Fig. 12). However, as mentioned previously, the CFD analyses carried out, including the FLS model, only account for the inside surface of the blades and therefore neglect a large portion of the losses through the runner. 


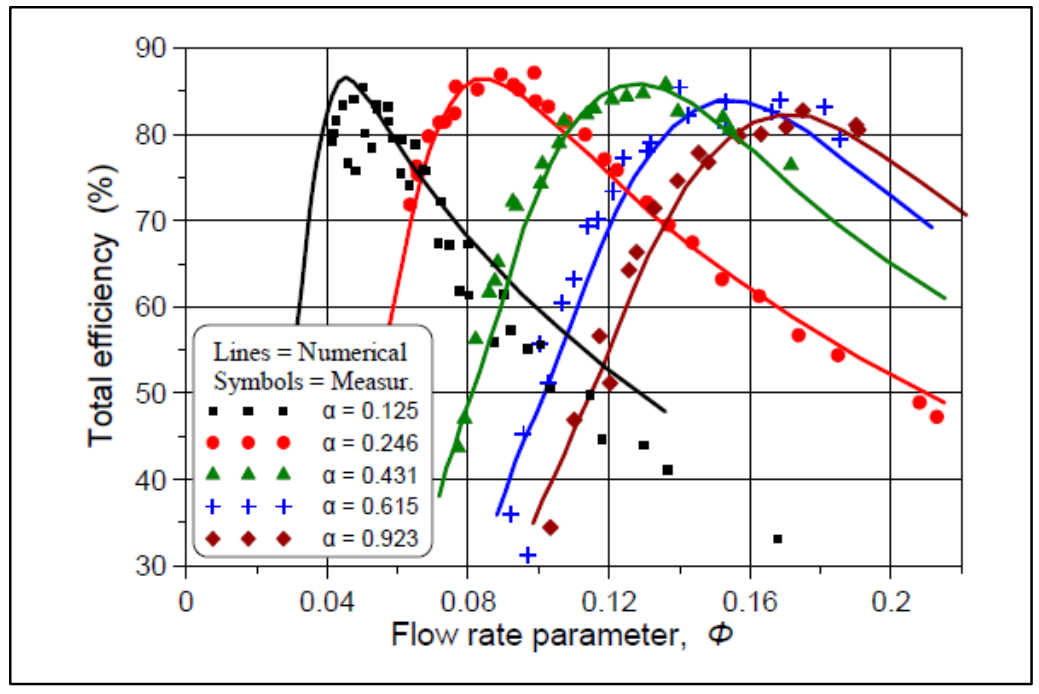

Fig. 12. Comparison between experimental and FLS numerical model results

In 2012, Correa et al., develop a methodology for the design of a Turgo turbine using Rankine Oviods, a type of three dimensional potential flows used to develop streamlines which are modified using various algorithms to predict the flow passing through the Turgo blades. The efficiency of this Turgo design is calculated as $80.8 \%$ [50].

This work was taken further by using the commercial CFD software ANSYS CFX 12.0 simulate the performance of this turbine. A very course mesh was used for this analysis with the full turbine, with all 20 blades, as well as the entire casing being simulated using just over 2 million elements [87].

Although the results showed the relative streamline angles to be similar to the theoretical calculations, the very large elements used in the path of the jet mean that the volume fraction of water to reach the jets is only between 0.15 and 0.30 . This means that almost the entire resolution of the jet is lost between the nozzle and the runner as there are insufficient elements to capture the shape of the jet. The conclusion of this paper points towards a transient analysis of the turbine as opposed to the frozen rotor setup used in order to establish a better approximation of the torque and the efficiency [87].

Since the last patent for the Gilkes Turgo design expired, there have been a number of companies who have adopted the Turgo design including Heidra [88] and Hydrover Turbines [89] in the UK, Wasserkraft Volk AG [90] in Germany, Hartvigsen Hydro [91] in the USA, Varspeed Hydro [92] and LP Electric [93] in Romania, HS Dynamic [94] in China and several others specialising largely in low cost micro and pico hydro solutions.

An optimisation study of a Pico scale Turgo operating at a head of 1-3.5m was carried out in 2013 by Williamson et al. This study uses a 2D quasi-steady state model to arrive at a baseline design and carries out two experimental optimisation studies looking at the jet angle, position, diameter and head 
as well as the shape of the blades. The study claims an efficiency of $91 \%$ at a very low head of $3.5 \mathrm{~m}$ [95].

\section{Discussion and Suggestions}

\subsection{0pportunities for more Turgo development}

This review has shown the significant development which has been carried out on the Turgo turbine during the past century and how this has evolved as CFD analysis and computing techniques have made the detailed numerical calculation of the associated flows possible.

It has shown that although we are beginning to use CFD analysis of this complex case, it has yet to be utilised to its full potential. A complete analysis of the Turgo turbine using CFD, capturing the high speed, highly turbulent, multiphase flow across the blades is yet to be carried out. Research on Pelton turbines have shown that using Eulerian techniques it is possible to develop a CFD model which can accurately describe the flow across the Turgo runner, calculate the torque developed, the efficiency and capture small changes in the design in a reasonable timescale.

With the continual improvements to computer processing speeds and CFD codes, these complex simulations are being run in shorter times and it is predicted that the future development of the Turgo turbine will be based around these numerical analyses.

\subsection{General methodology for impulse turbine analysis}

No single best CFD software, code or methodology can be identified for impulse turbine development as this decision depends on the design stage and available resources. Few different development directions can be identified worldwide and are summarised in Table 1. The intention of this table is to guide the engineers or researchers interested in the development of Pelton or Turgo turbines and help to make the decision which code or methodology is the most suitable for them.

Majority of the reviewed publications on modelling of the rotating runner, which is the most complex part, suggest that CFX is the code that provides accurate and stable results. The close second in terms of a number of publications is Fluent. However, both of these codes are mesh based therefore require high computational resources. Furthermore they are not open source.

There are some options for researchers interested in code development or with limited budgets. In this case feasible alternatives are SPH, FLS or OpenFOAM. The closest option to CFX or Fluent is the open source code named OpenFOAM, another mesh based CFD code. However, further research is required before this can be used for Pelton or Turgo development. Now SPH or FLS is an entirely different alternative as they are based on mesh free (Lagrangian) specification of the flow. These two 
methods are not as accurate as CFX or Fluent but they are much faster making them very useful at initial design stage where large numbers of designs are evaluated. Nevertheless, for final design comparison it is suggested to use CFX. This suggestion is based on the successful application of CFX by various independent researchers.

In most of the recently published CFD studies of Pelton and Turgo turbines, the k- $\omega$ SST model is used for turbulence and the Homogeneous or Volume of Fluid method with Free surface for multiphase modelling.

\section{Conclusions}

This review has shown that there has been a significant increase in the use of CFD for the development of impulse turbines over the recent years with the focus being largely on Pelton turbines and some Turgo analysis being carried out. With the constant improvements to the CFD codes being used and the increase in the available computational resources required for these complex simulations, recent studies are showing more holistic analyses capturing more of the complex flow phenomenon encountered in these devices. The available literature has shown that the Pelton simulations are getting closer to experimental results and there is a scope for a more detailed analysis of the flow in a Turgo runner using similar methodologies. 
Table 1 - Comparison of CFD methods and software used for Impulse turbine modelling.

\begin{tabular}{|c|c|c|c|c|c|c|c|c|c|c|c|}
\hline \multicolumn{4}{|c|}{ Code Description } & \multicolumn{3}{|c|}{$\begin{array}{c}\text { Problems Analysed } \\
\text { (Number of Publications) }\end{array}$} & \multicolumn{2}{|c|}{ Capabilities } & \multicolumn{2}{|c|}{ Usage in the Field } & \multirow[t]{2}{*}{ Comment } \\
\hline & 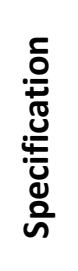 & 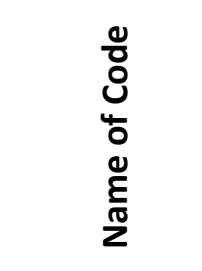 & 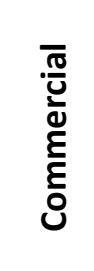 & 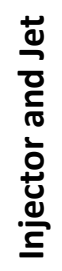 & 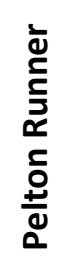 & 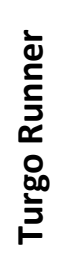 & 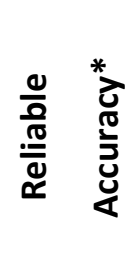 & 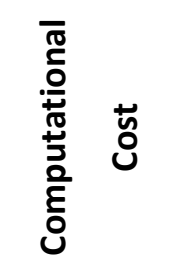 & 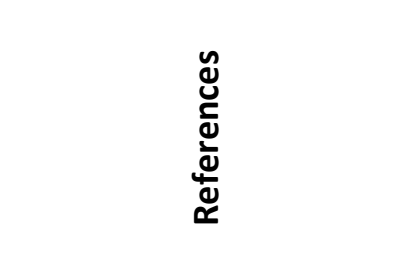 & 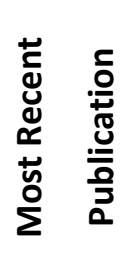 & \\
\hline \multirow{4}{*}{$\frac{\frac{c}{\frac{\pi}{2}}}{\frac{d}{5}}$} & \multirow{4}{*}{ 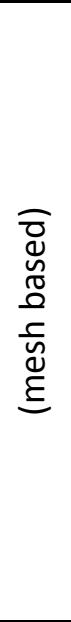 } & CFX & Yes & 3 & 12 & 1 & Yes & High & $\begin{array}{c}{[22,55-57,59-64,66-69,} \\
71,96]\end{array}$ & 2015 & $\begin{array}{l}\text { - } \text { Good accuracy* } \\
\text { - Suitable for optimisation } \\
\text { - } \text { Most widely used for rotating } \\
\text { runner simulations }\end{array}$ \\
\hline & & Fluent & Yes & 4 & 4 & 2 & Yes & High & {$[53,54,56-59,70,71]$} & 2015 & $\begin{array}{l}\text { - } \quad \text { Good accuracy* } \\
\text { - } \quad \text { Suitable for optimisation }\end{array}$ \\
\hline & & OpenFOAM & No & - & 1 & - & No & High & [73] & 2013 & $\begin{array}{l}\text { - Open source } \\
\text { - No successful attempts to model } \\
\text { impulse turbines }\end{array}$ \\
\hline & & Flow-3D & Yes & 1 & - & - & No & High & {$[22]$} & 2000 & $\begin{array}{lll}\text { - No recent publications on } & \text { on } \\
\text { impulse turbine simulations } & \end{array}$ \\
\hline \multirow{4}{*}{ 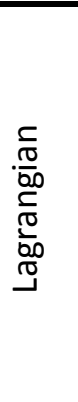 } & \multirow{4}{*}{ 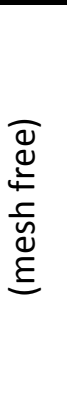 } & SPH & No & - & 3 & 2 & No & Moderate & {$[77-79,97,98]$} & 2013 & $\begin{array}{l}\text { - Open source } \\
\text { - Useful for initial design stage }\end{array}$ \\
\hline & & FLS & No & - & 3 & 1 & No & Low & {$[49,71,81,82]$} & 2014 & - Useful for initial design stage \\
\hline & & FVPM & No & - & 2 & - & No & Moderate & [99] & 2013 & $\begin{array}{l}\text { - Combines attractive features of } \\
\text { Lagrangian and Eulerian }\end{array}$ \\
\hline & & MPS & No & - & 1 & - & No & Low & [83] & 2009 & $\begin{array}{l}\text { - No recent publications on } \\
\text { impulse simulations }\end{array}$ \\
\hline
\end{tabular}

*this assessment of accuracy is concentrating on modelling of impulse turbines and is based on the findings of available publications. 


\section{References}

1. European Commission, Directive 2009/28/EC of the European Parliament and of the Council of 23 April 2009 on the promotion of the use of energy from renewable sources and amending and subsequently repealing Directives 2001/77/EC and 2003/30. Official Journal of the European Union Belgium, 2009.

2. United Nations Framework Convention on Climate Change. Fact sheet: The Kyoto Protocol. 2011 [cited 2015 March 17]; Available from: http://unfccc.int/files/press/backgrounders/application/pdf/fact sheet the kyoto protocol.pdf.

3. European Renewable Energy Council, Renewable Energy in Europe: Markets, Trends, and Technologies. 2nd ed. 2010: Earthscan.

4. National Grid. Data explorer. 2014 [cited 2015 March 17]; Available from: http://www2.nationalgrid.com/uk/Industry-information/Electricity-transmission-operationaldata/Data-Explorer/.

5. British Hydropower Association. Hydropower: Opportunities, challenges \& sharing best practice. The British Hydropower Association perspective. 2010 [cited 2015 March 17]; Available from: http://www.ciwem.org/media/142437/The\%20British\%20Hydropower\%20Association\%20Persp ective.pdf.

6. Aggidis, G.A., et al., The costs of small-scale hydro power production: Impact on the development of existing potential. Renewable Energy, 2010. 35(12): p. 2632-2638.

7. Aggidis, G.A. Performance Envelopes of Hydro Turbines. 2010 [cited 2015 March 17]; Available from: http://www.engineering.lancs.ac.uk/lureg/nwhrm/engineering/.

8. Pelton, L.A. 1880: US.

9. Nechleba, M., Hydraulic turbines: Their design and equipment. 1957, Prague: Artia.

10. Mosonyi, E., Water Power Development: High-head power plants. 3rd ed. Water Power Development. Vol. 2b. 1991, Budapest: Akademiai Kiado. 1074.

11. Patel, K., et al. Development of Pelton turbine using numerical simulation. in 25th IAHR Symposium on Hydraulic Machinery and Systems. 2010. IOP Conf. Series: Earth and Environmental Science 12 (2010) 012048.

12. Aggidis, G.A. and A. Židonis, Hydro turbine prototype testing and generation of performance curves: Fully automated approach. Renewable Energy, 2014. 71: p. 433-441.

13. Keck, H. and M. Sick, Thirty years of numerical flow simulation in hydraulic turbomachines. Acta mechanica, 2008. 201(1-4): p. 211-229.

14. Sick, M., et al. Recent Examples of Modern CFD - Methods and Their Application in Practical Turbine Designs. in 23rd CADFEM Users' Meeting 2005 International Congress on FEM Technology with ANSYS CFX \& ICEM CFD Conference. 2005.

15. Staubli T., A.A., Weibel P., Bissel C., Parkinson E., Leduc J., Leboeuf F. Jet quality and Pelton efficiency. in Hydro 2009. 2009. Lyon.

16. Peron, M., et al., Importance of jet quality on Pelton efficiency and cavitation, in IGHEM2008. 2008: Milan, Italy.

17. Marongiu, J.C., P. Maruzewski, and E. Parkinson, Modelling the flow in a Pelton turbine. SPHERIC newsletter, 2005: p. 8-9. 
18. Staubli, T., et al. Efficiency increase by jet quality improvement and reduction of splashing water in the casing of Pelton turbines. in 16 th International Seminar on Hydropower Plants. 2010.

19. Pelton Water Wheel Company, The Pelton Water Wheel... Embracing in Its Variations of Construction and Application the Pelton System of Power. 1898, San Francisco.

20. Davidson, S.C., Impact-wheel or turbine, U.S.P.a.T. Office, Editor. 1900, Google Patents: Washington, DC.

21. Avellan, F., et al. Flow Calculations in Pelton Turbines,-Part 2: Free Surface Flows. in Proceedings of the19th IAHR Symposium, Singapore, Republic of Singapore. 1998.

22. Muggli, F., et al. Numerical and experimental analysis of Pelton turbine flow. Part 2: the free surface jet flow. in 20 th IAHR Symposium. 2000.

23. Sick, M., et al. New challenges in pelton research. in Hydro 2000 Conference. 2000. Bern.

24. Sick, M., et al. Numerical and experimental analysis of Pelton turbine flow. Part 1: Distributor and Injector. in XX IAHR Symposium, Charlotte. 2000.

25. Parkinson, E., et al. Experimental and numerical investigations of the free jet flow at a model nozzle of a Pelton turbine. in Proceedings of the XXI IAHR Symposium on Hydraulic Machinery and Systems. 2002. Lausanne.

26. Brekke, H., A general study on the design of vertical Pelton turbines. 1984, Turboinstitut: Ljubljana.

27. Hana, M., Numerical analysis of non-stationary free surface flow in a Pelton bucket. 1999, Norwegian University of Science and Technology: Trondheim.

28. Kvicinsky, S., et al. Experimental and numerical analysis or free surface flows in a rotating bucket. in The proceeding of the 21st IAHR Symposium on hydraulic machinery and systems. 2002.

29. Parkinson, E., et al., Analysis of Pelton turbine flow patterns for improved runner-component interaction. International Journal on Hydropower \& Dams, 2002. 9(5): p. 100-103.

30. Parkinson, E., et al., Unsteady analysis of a Pelton runner with flow and mechanical simulations. International Journal on Hydropower \& Dams, 2006. 13(2): p. 101-105.

31. Solemslie, B. and O. Dahlhaug. A reference Pelton turbine design. in IOP Conference Series: Earth and Environmental Science. 2012. IOP Publishing.

32. Fulton, A., Present Tendencies in Water Turbine Machinery. Proceedings of the Institution of Mechanical Engineers, 1937. 135(1): p. 387-444.

33. Prášil, F., Results of Experiments with Francis Turbines and Tangential (Pelton) Turbines. Proceedings of the Institution of Mechanical Engineers, 1911. 81(1): p. 647-679.

34. Ecopolis. Pelton Turbine HHP - H. 2010 [cited 2015 March 17]; Available from: http://www.ecopolisla.com/en/hydro-power/products/turbines/detail-pelton-turbine-hhp---h-50/.

35. Eisenring, M., Micro pelton turbines. Harnessing Water Power on a Small Scale. Vol. 9. 1991, St. Gallen: Swiss Center for Appropriate Technology.

36. Thake, J., The micro-hydro Pelton turbine manual: design, manufacture and installation for small-scale hydro-power. 2000: ITDG publishing London.

37. Atthanayake, I.U., Analytical study on flow through a Pelton turbine bucket using boundary layer theory. International Journal of Engineering and Technology, 2009. 9(9): p. 241-245.

38. Nasir, B.A., Design of High Efficiency Pelton Turbine for Micro-Hydropower Plant. International Journal of Electrical Engineering \& Technology (IJEET), 2013. 4(1): p. 171-183. 
39. Crewdson, E. Design and Performance of a New Impulse Water-Turbine. in Minutes of Proceedings of the Institution of Civil Engineers. 1922. The Institution of Civil Engineers.

40. Gibson, A.H., Hydraulics And Its Applications. 1908: D. van Nostrand Company.

41. Wilson, P.N., A High Speed Impulse Turbine. 1967.

42. Webster, J., Analysis of Jet Type Impulse Turbines. Water Power, 1971: p. P287-P292.

43. Webster, J., Flow patterns related to jet-type impulse turbines. Water Power, 1972: p. P243-252.

44. Webster, J., Hydraulic impulse turbines of high specific speed. Water Power, 1973: p. P250-260.

45. Crewdson, E., Improvements in Water Turbines, in May 10, 1920, The Patent Office, Editor. 1920: London, UK.

46. Jackson, E.A., Improvements in Water Turbines, in July 7th 1937, The Patent Office, Editor. 1937: London, UK.

47. Jackson, E.A., Improvements in Water Turbines, in October 9th 1963, The Patent Office, Editor. 1963: London, UK.

48. Webster, J., Flow patterns related to jet-type impulse turbines. 1972.

49. Anagnostopoulos, J.S. and D.E. Papantonis, Flow Modelling and Runner Design Optimization in Turgo Water Turbines. 2007. P206-211.

50. Correa, J.L.C., et al., Design Procedure for a Turgo Type Turbine Using a Three-Dimensional Potential Flow, in ASME Turbo Expo 2012: Turbine Technical Conference and Exposition. 2012, ASME Proceedings | Turbomachinery: Copenhagen, Denmark, June 11-15, 2012.

51. Cobb, B.R. and K.V. Sharp, Impulse (Turgo and Pelton) turbine performance characteristics and their impact on pico-hydro installations. Renewable Energy, 2013. 50(0): p. 959-964.

52. Židonis, A. and G. Aggidis, State of the art in numerical modeling of Pelton turbines. Renewable and Sustainable Energy Reviews, 2015. 45(May 2015): p. 135-144.

53. Veselý, J.V., M, A case study of upgrading $62.5 \mathrm{MW}$ Pelton turbine, in Proceedings of International Conference: IAHR 2001. 2001: Prague.

54. Matthias, H.B. and O. Promper, Numerical simulation of the free surface flow in Pelton turbines, in The 6th International Conference on Hydraulic Machinery and Hydrodynamics. 2004: Timisoara.

55. Staubli, T., et al., Jet quality and Pelton efficiency. Proceedings of Hydro 2009 ProgressPotential-Plans, 2009.

56. Xiao, Y., et al., Numerical and experimental analysis of the hydraulic performance of a prototype Pelton turbine. Proceedings of the Institution of Mechanical Engineers, Part A: Journal of Power and Energy, 2014. 228(1): p. 46-55.

57. Benzon, D., et al., Impulse turbine injector design improvement using Computational Fluid Dynamics. Journal of Fluids Engineering, 2015. 137(4): p. 041106.

58. Zoppe, B., et al., Flow analysis inside a Pelton turbine bucket. Journal of turbomachinery, 2006. 128(3): p. 500-511.

59. Klemensten, L.A., An experimental and numerical study of the free surface Pelton bucket flow. 2010, Norwegian University of Science and Technology: Trondheim.

60. Gupta, V. and V. Prasad, Numerical investigations for jet flow characteristics on pelton turbine bucket. International Journal of Emerging Technology and Advanced Engineering, 2012. 2(7): p. 364-370. 
61. Gupta, V., V. Prasad, and R. Khare, Effect of Jet Shape on Flow and Torque Characteristics of Pelton Turbine Runner. International Journal of Engineering Research and Applications, 2014. 4(1): p. 318-323.

62. Perrig, A., et al., Flow in a Pelton turbine bucket: numerical and experimental investigations. Journal of Fluids Engineering, 2006. 128(2): p. 350-358.

63. Perrig, A., Hydrodynamics of the free surface low in Pelton turbine buckets, in À LA FACULTÉ DES SCIENCES ET TECHNIQUES DE L'INGÉNIEUR. 2007, École polytechnique fédérale de Lausanne.

64. Santolin, A., et al., Numerical investigation of the interaction between jet and bucket in a Pelton turbine. Proceedings of the Institution of Mechanical Engineers, Part A: Journal of Power and Energy, 2009. 223(6): p. 721-728.

65. Janetzky, B., et al. Numerical simulation of the flow in a Pelton bucket. in Proceedings of 19th IAHR Symposium. 1998.

66. Jošt, D., A. Lipej, and P. Meznar. Numerical Prediction of Efficiency, Cavitation and Unsteady Phenomena in Water Turbines. in ASME 2008 9th Biennial Conference on Engineering Systems Design and Analysis. 2008. American Society of Mechanical Engineers.

67. Jošt, D., P. Mežnar, and A. Lipej. Numerical prediction of Pelton turbine efficiency. in 25th IAHR Symposium on Hydraulic Machinery and Systems. 2010. IOP Conf. Series: Earth and Environmental Science 12 (2010) 012080.

68. Barstad, L.F., CFD Analysis of a Pelton Turbine. 2012, Norwegian University of Science and Technology: Trondheim.

69. Panthee, A., H.P. Neopane, and B. Thapa, CFD Analysis of Pelton Runner.

70. Xiao, Y., et al. Numerical simulation of unsteady free surface flow and dynamic performance for a Pelton turbine. in IOP Conference Series: Earth and Environmental Science. 2012. IOP Publishing.

71. Židonis, A., et al., Parametric Optimisation of Two Pelton Turbine Runner Designs Using CFD. Journal of Hydrodynamics, Ser. B, 2014(In Press).

72. OpenFOAM Foundation. OpenFOAM User Guide, Version 2.1.1. 2012 [cited 2015 March 17]; Available from: http://www.openfoam.org/version2.1.1/.

73. Rygg, J.R., CFD Analysis of a Pelton Turbine in OpenFOAM. 2013, Norwegian University of Science and Technology: Trondheim.

74. Batchelor, G.K., An introduction to fluid Dynamics. 1973: Cambridge University Press.

75. Lamb, H., Hydrodynamics. 1994: Cambridge University Press.

76. Munson, B.R., D.F. Young, and T.H. Okiishi, Fundamentals of Fluid Mechanics. 5th ed. 2005: John Willey \& Sons, Inc.

77. Marongiu, J.C., et al., Free surface flows simulations in Pelton turbines using an hybrid SPHALE method. Journal of Hydraulic Research, 2010. 48(S1): p. 40-49.

78. Furnes, K., Flow in Pelton turbines. 2013, Norwegian University of Science and Technology: Trondheim.

79. Koukouvinis, P.K., J.S. Anagnostopoulos, and D.E. Papantonis, Flow Analysis Inside a Pelton Turbine Bucket Using Smoothed Particle Hydrodynamics in HYDRO International Conerence. 2010. 
80. Anagnostopoulos, J.S. and D.E. Papantonis, Flow modeling and runner design optimization in Turgo water turbines. World Academy of Science, Engineering and Technology, 2007. 28: p. 206-211.

81. Anagnostopoulos, J.S. and D.E. Papantonis, A numerical methodology for design optimization of Pelton turbine runners. HYDRO 2006, 2006: p. 25-27.

82. Anagnostopoulos, J.S. and D.E. Papantonis, A fast Lagrangian simulation method for flow analysis and runner design in Pelton turbines. Journal of Hydrodynamics, Ser. B, 2012. 24(6): p. 930-941.

83. Nakanishi, Y., T. Fujii, and S. Kawaguchi, Numerical and experimental investigations of the flow in a stationary Pelton bucket. Journal of Fluid Science and Technology, 2009. 4(3): p. 490-499.

84. Koukouvinis, P.K., J.S. Anagnostopoulos, and D.E. Papantonis, SPH modelling of a Turgo turbine, in SPHERIC newsletter 11th issue - December 2010. 2010, http://wiki.manchester.ac.uk/spheric/: SPH European Research Interest Community.

85. Koukouvinis, P.K., J.S. Anagnostopoulos, and D.E. Papantonis, SPH Method used for Flow Predictions at aTurgo Impulse Turbine: Comparison with Fluent, in World Academy of Science, Engineering and Technology 55 2011. 2011.

86. Anagnostopoulos, J.S., et al., OPTIMAL DESIGN AND EXPERIMENTAL VALIDATION OF A TURGO MODEL HYDRO TURBINE, in Proceedings of the 11th Conference on Engineering Systems Design and Analysis, ESDA2012, Editor. 2012: Nantes, France.

87. Correa, J.L.C., J.D. Andrade, and M. Asuaje, A Preliminary Analysis of a Turgo Type Turbine CFD Simulation Designed With an Integrated Dimensional Methodology, in 24th Symposium on Fluid Machinery. 2012: Rio Grande, Puerto Rico, USA, July 8-12, 2012.

88. Ltd, H. http://www.heidra.co.uk/. 2015 10/02/15].

89. Turbines, H. http://hydrover.co.uk/. 2015 10/02/15].

90. AG, W.V. http://www.wkv-ag.com/start.html. 2015 10/02/15].

91. Hydro, H. http://www.h-hydro.com/. 2015 10/02/15].

92. Varspeed Hydro Ltd. http://www.varspeedhydro.com/index.html. 2015 10/02/15].

93. Electric, L. http://www.lpelectric.ro/en/about_en.html. 2015 10/02/15].

94. Energy, H.D. http://www.hs-dynamics.com/. 2015 10/02/15].

95. Williamson, S.J., B.H. Stark, and J.D. Booker, Performance of a low-head pico-hydro Turgo turbine. Applied Energy, 2013. 102(0): p. 1114-1126.

96. Gupta, V., R. Khare, and V. Prasad, Performance Evaluation of Pelton Turbine: A Review. Hydro Nepal: Journal of Water, Energy and Environment, 2014. 13: p. 28-35.

97. Koukouvinis, P., J.S. Anagnostopoulos, and D.E. Papantonis, SPH modelling of a Turgo turbine, in SPHERIC newsletter 11th issue - December 2010. 2010, http://wiki.manchester.ac.uk/spheric/: SPH European Research Interest Community.

98. Koukouvinis, P., J.S. Anagnostopoulos, and D.E. Papantonis, SPH Method used for Flow Predictions at aTurgo Impulse Turbine: Comparison with Fluent, in World Academy of Science, Engineering and Technology 55 2011. 2011.

99. Vessaz, C., E. Jahanbakhsh, and F. Avellan. Flow simulation of a Pelton bucket using finite volume particle method. in IOP Conference Series: Earth and Environmental Science. 2014. IOP Publishing. 